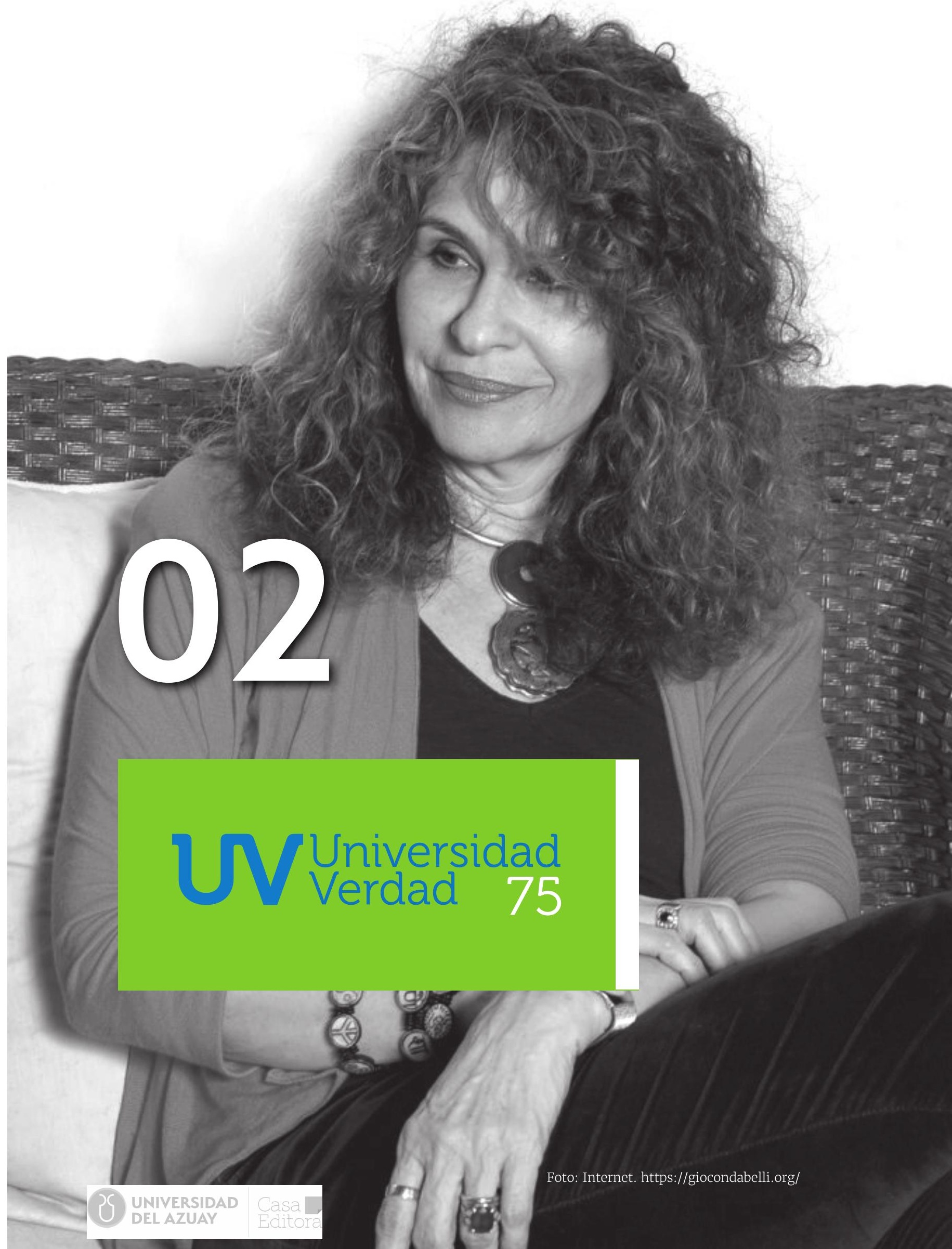




\section{GÉNERO, MEMORIA E IDENTIDAD POLÍTICA EN LA NARRATIVA DE GIOCONDA BELLI}

\section{Gender, memory and political identity in the narrative of Gioconda Belli}

iD Dra. Karen Barahona. Profesora de Estudios Hispánicos. Universidad de Baldwin Wallace. (Estados Unidos) (kbarahon@bw.edu) (https://orcid.org/0000-0001-79555540)

\section{Resumen}

Debido a los eventos políticos y revolucionarios de los setenta en Centroamérica, específicamente en Nicaragua, la mujer tuvo que redefinir su búsqueda de igualdad desde una perspectiva personal y nacional. Considerando los eventos en un contexto histórico de violencia y caos, el propósito de esta investigación es analizar la representación de la mujer desde una perspectiva literaria revolucionaria-sandinista y la conexión con su pasado indígena precolombino, a través de la memoria. La escritora nicaragüense Gioconda Belli trata esta temática en sus dos obras La mujer habitada (1988) y Sofía de los presagios (1990). En las novelas las protagonistas dan voz a la mujer nicaragüense que buscó una participación política durante el desarrollo de la revolución sandinista, estas hacen memoria a la mujer indígena que luchó durante la conquista española, que sufren marginalización por su clase y su etnia.
A través de estas representaciones de marginalización Belli denuncia el liderazgo sandinista, sus fracasos y la agenda política de falta de apoyo a la mujer en la revolución. Para explicar la contribución de funciones específicas de la literatura testimonial hacia la construcción de una identidad nacional y una construcción indígena, en este trabajo se expone la teoría de los discursos testimoniales de Linda Craft, Laura Barbas-Rhoden y Margaret Randall, para demonstrar cómo las obras de Belli producen una unión entre la mujer sandinista y su pasado indígena, critican movimientos revolucionarios, reescriben la historia para reivindicar a la mujer y su etnia como sujeto histórico por su participación revolucionaria y precolombina, y recrean memorias no solo para referirse al pasado sino con la convicción de albergar el recuerdo de la participación de la mujer en la revolución y la conquista española. 


\begin{abstract}
Due to certain revolutionary and political events in Central America in the late seventies, women had to redefine their search for equality from a national and a personal perspective. Considering the historical context of revolution, violence and chaos in the region, the purpose of this work is to analyze the representation of women from a literary perspective, the relationship between the Sandinista revolution and women's connection with their indigenous past through memory. In this sense, Gioconda Belli's literary works that share these concerns are La mujer habitada (1988) and Sofía de
\end{abstract}

los presagios (1990). To explain the contribution of specific functions of testimonial literature toward building a national and individual identity, this work analyzes the testimonial discourse theories of Linda Craft, Laura Barbas-Rhoden and Margaret Randall to demonstrate how Belli's work: Produce a union between Sandinista revolutionary women and their indigenous past; Critiques Sandinista patriarchal discourse; rewrites history to vindicate women as historical subjects due to revolutionary involvement and; Recreates memories of women's participation in the Sandinista revolution and the Spanish Conquest.

\section{Palabras clave}

Género, identidad política, subjetividad, revolución sandinista.

\section{Keywords}

Gender, political identity, subjectivity, Sandinista Revolution

\section{1.}

Introducción. En términos políticos, en 1987 comienza la destitución de la mujer en el sandinismo, cuando se produce la guerra de los Contra, y en 1990 comienza la presidencia de Violeta Chamorro ${ }^{1}$. Belli responde a estos eventos con la publicación de las novelas La mujer habitada (1988) y Sofía de los presagios (1990). Con el triunfo de la revolución sandinista se puso fin a una dictadura de 36 años, que marcó en la mujer nicaragüense una esperanza de redefinir su identidad política mediante la participación revolucionaria. A diferencia del resto de los países centroamericanos, Nicaragua, por su protagonismo en la revolución y el involucramiento de la mujer en la línea de fuego, proporciona un contexto sociopolítico propicio para entender la trascendencia del paso de la mujer, del espacio privado al público. Ante esta problemática de la adaptación sociopolítica de la mujer, la socióloga Maxime Molyneux -en Women's movements in international perspective: Latin America and Beyond (2003, p. 40)- postula la inquietud de la relación entre la revolución sandinista y la emancipación de la mujer: "For if women surrender their specific interests in the universal struggle for a different society, at what point are these interests rehabilitated and responded to by the revolutionary forces or by the new socialist state?" [Si las mujeres renuncian a sus intereses específicos en la lucha universal por una sociedad diferente, ¿en qué punto las fuerzas revolucionarias o el nuevo estado socialista rehabilitan y responden a estos intereses?].

En este ambiente de cambios políticos la revolución sandinista buscó la participación de la mujer, por lo que entraron en relación dos intereses que discrepaban: por un lado, la mujer tenía el interés de emanciparse, y por otro, la revolución quería consolidar el poder.

En respuesta a la situación política de su país, la escritora Gioconda Belli reflejó en varias de sus obras al sandinismo como factor sociopolítico que marcaba el papel de la mujer nicaragüense durante los años 1974-1990 para determinar hasta qué punto se consideraron los intereses de la mujer en la revolución sandinista.

1. Katherine Isbester, Still Fighting, Pittsburgh, PA, University of Pittsburgh Press, 2001, p. 64. 


\section{2.}

Materiales y métodos. El propósito de este trabajo es analizar la representación literaria de la mujer desde una perspectiva revolucionaria y su conexión con su pasado indígena, a través de la memoria en las novelas testimoniales de La mujer habitada (1988) y Sofía de los presagios (1990). Ambas protagonistas, Lavinia y Sofía, sufren marginalización por su género y clase, hacen memoria de sus antepasadas indígenas y buscan una participación política durante el desarrollo de los movimientos revolucionarios. Para explicar la contribución de estas funciones específicas de la literatura testimonial, este trabajo parte de los estudios de Linda Craft, Laura Barbas-Rhoden y Margaret Randall sobre la denuncia de la clasificación de la mujer como el "otro", el uso de la memoria para la recuperación de la historia y la recreación de las voces olvidadas del pasado. La escritora nicaragüense se refiere a su narrativa en primera persona, es decir, se vuelve el sujeto de la narración; para conseguir este objetivo utiliza la memoria colectiva de mujeres, uniéndola a su propia historia e individualizándose (Lasarte Leonet, 2013).

\section{3.}

Resultados. Según postula Craft (1997) en su estudio Novels and Testimony in Central America, la función del discurso testimonial en las obras es la representación del "otro" que en el contexto centroamericano incluye "peasants, indigenous peoples, women, children, homosexuals, the poor, political prisoners, guerilla fighters" [campesinos, indígenas, mujeres, niños, homosexuales, pobres, presos políticos, guerrilleros] (p. 4). Belli específicamente denuncia la categorización de la mujer como el "otro" representando a Itzá como la mujer indígena en La mujer habitada y a la madre de origen paya en Sofía de los presagios como modelos que inspiran a las protagonistas para resistir a los prejuicios sociales y al machismo.

Para clarificar los orígenes indígenas hay que decir que la palabra maya itzá significa aguas encantadas. Itzá también es un grupo étnico guatemalteco que habla el lenguaje itzá y vive en la región del Petén en Guatemala, en los alrededores de la ciudad de Flores junto al lago Itzá. Los itzá son descendientes de linaje maya y dominaron la península de Yucatán en el período posclásico de la cronología mesoamericana. Los itzá posiblemente se originaron en el período clásico y migraron a Yucatán. Desde su capital, Chichen Itzá establecieron un imperio de encomienda que llegaba hasta Honduras. En La mujer habitada Itzá es un personaje ficticio creado por Belli, que posiblemente usó ese nombre inspirada en el grupo étnico (Porter Weaver, 1993).

Por otra parte, los payas en Honduras vivían originalmente en la costa hondureña de La Moskitia, desde donde fueron perseguidos por los conquistadores españoles y miskitos. Miles de personas murieron y los otros huyeron hacia el corazón de la selva. Actualmente los payas en Honduras viven más al interior, en el distrito de Olancho, principalmente en el municipio de Dulce Nombre de Culmi y la aldea de San Esteban. El resto vive en los distritos de Colón y Gracias a Dios. Ellos se llaman a sí mismos pech (muchos los llaman payas), que significa gente, pero solo se refiere a su propia raza, para nombrar a otras personas utilizan "Hakua-Pech", que significa "otras personas" (Ferguson \& Adams, 2001, p. 9). Ambos grupos étnicos sirven con el propósito de representar al "otro" de la mujer indígena en las obras de Belli.

La segunda función testimonial en las obras es el uso de la memoria, que según Barbas-Rhoden y Margaret Randall tiene los propósitos de la recuperación de la historia y la recreación de la memoria para compartir las voces del pasado. En referencia al primer uso, Belli se apropia de la historia para reescribir la participación de la mujer como sujeto histórico. Todo comienza cuando las protagonistas enfrentan su carencia de antecedente cultural o biológico y por medio de la memoria buscan su pasado indígena o el recuerdo de su madre para hacer conexión con sus raíces. Sobre esto Barbas-Rhoden (2003) en Writing Women in Central America destaca que:

All of Belli's narratives share a concern with coming of age and are stories of limitations, rebellion and a quest for identity and subjectivity. And despite the differences among Belli's fiction, there is one recurring narrative throughout: the confrontation of women of their lack of history and their search for empowerment through a connection with their past. [Todas las narraciones de Belli comparten una preocupación con la mayoría de edad y son historias de limitaciones, rebeliones y una búsqueda de identidad y sub- 
jetividad. Y a pesar de las diferencias entre la ficción de Belli, hay una narrativa recurrente: la confrontación de las mujeres por su falta de historia y su búsqueda de poder a través de una conexión con su pasado]. (p. 49)

Este proceso de recuperación del pasado en las protagonistas lo vemos repetido a lo largo de las novelas, y es causado por la ausencia de un antecedente cultural o biológico con el propósito de salir de la crisis de marginalización.

Margaret Randall en Walking to the edge: essays of resistance (1991) y Sandino's Daughters. Testimonies of Nicaraguan Women in Struggle (1994), analiza testimonios de mujeres nicaragüenses que lucharon en el sandinismo y sus memorias. El uso de la memoria según Randall (1991), es el de recuperar y recrear memorias para futuras generaciones. Además, enfatiza el uso de la memoria en el discurso testimonial como elemento importante para la mujer:

And memory is vital. It occupied a new, almost sacred, place in our writing; in our poetry, prose, essays, and journalistic efforts. Even in our images; photography and other visual art forms. We came to understand how a retrieval of our own memory was essential, not simply for the language of our lives, but for the very meaning of that language, the nurturing of life itself. And so we gave thought to ways in which we might uncover, discover, and recreate the memories of those whose voices we passed on. It was not a matter of remembering more. It was a matter of remembering differently, unfettered by what men have deemed worthy of recording, unaltered by male interpretation, uncluttered by the male system of rewards of achievement according to their values. [Y la memoria es vital. Ocupaba un lugar nuevo, casi sagrado, en nuestra escritura; en nuestra poesía, prosa, ensayos y esfuerzos periodísticos. Incluso en nuestras imágenes; fotografía y otras formas de arte visual. Llegamos a comprender cómo era esencial la recuperación de nuestra propia memoria, no solo para el lenguaje de nuestras vidas, sino también para el significado mismo de ese idioma, el cuidado de la vida misma. Y entonces pensamos en formas en que podríamos destapar, descubrir y recrear los recuerdos de aquellos cuyas voces transmitimos. No se trataba de recordar más. Era una cuestión de acordarse de manera diferente, sin restricciones por lo que los hombres han considerado dignos de registrar, sin alteraciones por la interpretación masculina, sin estorbos por el sistema masculino de recompensas de sus logros según sus valores]. (p. 71)

Para Randall (1991) el acto de recordar, en la escritura de la mujer, construye discursos que retan, se desligan del patriarcado y reescriben la historia de la mujer como sujeto. Este elemento con el surgimiento del testimonio empieza a usarse no solo para recordar, también para recrear la memoria de la lucha revolucionaria y de lo que pudo ser. El proceso de Randall de "uncover, discover, recreate the memories of those whose voices we passed on" [destapar, descubrir, recrear los recuerdos de aquellos cuyas voces transmitimos] aplicado a las novelas de Belli resulta en sus textos como "memoriales al futuro" (p. 76), que Belli misma define así: "Siempre pensamos que la memoria debe referirse al pasado, pero es mi convicción que hay también una memoria, un memorial al futuro; que también albergamos el recuerdo de lo que puede llegar a ser" (1998, p. 327).

La mujer habitada (1988) es la primera novela de Belli que además marca una serie de protagonistas huérfanas, fuera de la línea patriarcal y en busca de su identidad. La novela desenvuelve la historia de Lavinia e Itzá y el paralelo de sus luchas revolucionarias. Itzá habita simbólicamente en el palo de naranjo de la casa de Lavinia. Cuando nacen los frutos, Lavinia toma de su jugo e Itzá entra en ella. Itzá fue una indígena que luchó y resistió durante la conquista española. La fuerza de Itzá, que habita en las venas de Lavinia, la motivará a continuar la lucha revolucionaria de sus antepasadas. Ambas protagonistas han abandonado a sus padres para iniciar una vida independiente, y rechazan la pasividad de las mujeres a su alrededor. En su unión esa mañana de desayuno dominical, Lavinia comienza su proceso de búsqueda de identidad y participación revolucionaria.

La novela fue escrita entre 1987-1988, en plena victoria de la revolución sandinista. Belli retrata los procesos de cambios revolucionarios en el país y a la mujer en busca de su subjetividad política:

Although one could say that Belli actually writes La mujer habitada from a position of relative power herself, enjoying the fruits of the Sandinista triumph of 1979 and laboring in the projects of the young revolutionary government, one 
stills feels a spirit of defiance in the text, a surge of pride in a victory that will not be surrender easily to the threat of counterrevolution. Neither Belli nor her compatriots are 'home free'; and certainly, her struggle against machismo goes on. [Aunque se podría decir que Belli en realidad escribe a La mujer habitada desde una posición de poder relativo, disfrutando de los frutos del triunfo sandinista de 1979 y trabajando en los proyectos del joven gobierno revolucionario, todavía se siente un espíritu de desafío en el texto, una oleada de orgullo en una victoria que no se rendirá fácilmente a la amenaza de la contrarrevolución. Ni Belli ni sus compatriotas están "sin hogar"; y ciertamente su lucha contra el machismo continua]. (Craft, 1997, p. 159)

Este espíritu de "derrota" al que se refiere Craft son las luchas a las que tiene Lavinia que enfrentar para liberarse de la opresión patriarcal y machista. Primero se encontrará desubicada en una sociedad con la cual no se puede identificar, y se da cuenta de que en lo político es pasiva. Luego, la inspiración indígena de Itzá, la conciencia para ser activa en la lucha revolucionaria y buscar su lugar en la historia.

Por medio de su relación con Felipe, Lavinia se da cuenta de que es controlada por él en dos áreas de su vida, la amorosa y la política. Su relación con Felipe estaba basada en el dominio y el control, en un nivel de desigualdad que no le permitía un propósito ni en lo personal ni en lo político. Felipe no la involucra en el movimiento revolucionario, y Lavinia se da cuenta. Le comparte esto a su amiga Flor. Flor le refiere: "que el Che había escrito que las mujeres eran ideales para cocineras y correos de la guerrilla; aunque después anduvo en Bolivia con una guerrillera llamada Tania. ¿Quién sería Tania? ¿la amaría el Che?" (Belli, 1994, p. 147). La idea de Flor denuncia el estereotipo causado por los hombres en la revolución, y la insistencia de mantener a la mujer en puestos al margen de la agenda política.

En una entrevista con Edward Hood en 1994 Belli comparte su intención de retratar la lucha del rol de género de la mujer y su implicación en la participación revolucionaria. Aparte de la relación de Felipe y Lavinia, la historia de Itzá refleja siglos de resistencia de la mujer y que la desigualdad en la sociedad es uno de los que le inspiró para escribir la novela:
El otro tema fundamental es de la mujer, ¿no? ¿Cuáles son las condiciones y las contradicciones y conflictos que se dan en la participación revolucionaria a partir del género? Lo puse en el caso de la mujer también. Es decir, a pesar de los siglos que separan a las dos mujeres protagonistas, se pueden identificar entre sí, porque el universo subordinado de la mujer, y la lucha que tiene que hacer para ganar su participación dentro de la sociedad es mucho mayor que la que tiene que dar el hombre. Esos temas fueron la motivación principal para escribir la novela $\mathrm{La}$ mujer habitada. (1994, p. 125)

El paralelo entre Lavinia e Itzá muestra siglos de lucha de la mujer para salir de la marginalización. Este esfuerzo ha sido y sigue siendo mayor que el del hombre para obtener una participación política. La historia de Itzá es una representación ficticia de la indígena, que tuvo que escaparse de su tribu para participar en la conquista española. Lavinia, de la misma manera, tuvo que llevar una doble vida con su clase social para ser militante.

La historia de Itzá y Yarince y sus luchas en la conquista española, sirven como la inspiración de Lavinia para luchar contra cada obstáculo que enfrenta a lo largo de la trama. Belli hace que Lavinia constituya su identidad política recordando un pasado compartido por un colectivo (la lucha indígena de la conquista española). Para llenar su vacío cultural y tener un propósito histórico busca involucrarse en la revolución (de la misma manera que lo hizo Itzá cuando buscó la lucha en la conquista). Como resultado, Belli crea una memoria cultural del recuerdo de Lavinia para transmitir esta memoria en la novela, marcándola como una historia de rebelión y búsqueda de identidad.

La guerrillera indígena le sirvió a Lavinia de inspiración para resistir los prejuicios sociales y el machismo, y buscar a su madre cultural en la revolución. Su mayor influencia fue la resistencia en combate y la negación de la maternidad. Flor también sabía de Itzá y le comparte a Lavinia sobre su rol en la conquista española:

Hay un Yarince indígena, cacique de los Boatos y Caribes, que luchó más de quince años contra los españoles. Es una historia hermosísima. Casi no se conoce la resistencia que hubo aquí. Nos han hecho creer que la colonia fue un período idílico, pero no hay nada más falso. Por cierto que, aun- 
que no se sabe si es leyenda o realidad, Yarince tuvo una mujer que peleó con él. Fue de las que se negaron a parir para no darles más esclavos a los españoles...Deberías leer sobre eso. (Belli, 1996, p. 143)

Esta negación a la maternidad es pasada a Lavinia justo en el momento en que deseaba involucrarse en la revolución. Negación que Itzá enfatiza así: "Nos negamos a parir...los españoles quemaron nuestros templos; hicieron hogueras gigantescas donde ardieron los códices sagrados de nuestra historia; una red de agujeros era nuestra herencia" (Belli, 1996, p. 138). Así lo justifica: "Yo recibí noticias de las mujeres de Taguzgalpa. Habían decidido no acostarse más con sus hombres. No querían parirles esclavos a los españoles" (Belli, 1996, p. 138). Como aclaración debo decir que no pretendo establecer un esencialismo de la resistencia mediante la negación de la maternidad; no obstante, lo aplicable para la resistencia en los casos de Itzá y Lavinia era la negación a la maternidad.

Esta negación a la maternidad presenta una tensión entre dos entidades de lucha, las indígenas y los soldados españoles, y su maternidad como desventaja puesto que para las mujeres indígenas eso significaba la esclavitud. De igual manera, la tensión entre Lavinia y el liderazgo revolucionario es que su maternidad significaría una destitución de su cargo y el retroceso que su participación ha logrado. Para Lavinia obtener su maternidad justo en el momento en que incrementaba la resistencia ponía en riesgo su liderazgo en la revolución.

Itzá se separa de su familia para luchar en la conquista española, acción que su madre no le perdona y ella recuerda: "Me pregunto qué quedará de nosotros, de mi madre a quien nunca más volví a ver después de que me fui con Yarince. Nunca entendió que no podía simplemente quedarme en casa. Jamás le perdonó a Citalcoatl que me enseñara a usar el arco y la flecha" (Belli, 1996, p. 20). Este paralelo lo vemos con Lavinia a inicios de la novela, cuando se separa de su madre para obtener un propósito histórico. Con el ejemplo de resistencia de Itzá, Lavinia se inspira para buscar esa misma identidad como sujeto histórico. Cuando finalmente se involucra en el frente, su vida pasa a tener un propósito revolucionario y cada área de su vida está orientada y enfocada para apoyar el proyecto de liberación nacional.
Antes de morir, Felipe le pidió que lo sustituyese "No porque lo hubiera querido. Por necesidad. Las mujeres entrarían a la historia por necesidad. Necesidad de los hombres que no se daban abasto para morir, luchar, para trabajar. Las necesitaban, a fin de cuentas, aunque solo lo reconocieran en la muerte" (Belli, 1996, p. 361). La muerte de Felipe tiene varios significados importantes, entre ellos: demostrar la necesidad de la participación de la mujer en la revolución, criticar la agenda revolucionaria regida por hombres y el comienzo de un proceso de participación revolucionaria que ha venido buscando Lavinia. Aunque hay una reivindicación en la novela de otorgar a la mujer sus funciones en la política, no obstante, permanece la jerarquía. Esta acción refleja la agenda revolucionaria regida por hombres y la jerarquía de poder entre los dos. La muerte de Lavinia, al final de la novela, simboliza la permanencia de la mujer en la lucha, representada por la unión de la savia del palo de naranjo donde está Itzá y la sangre de Lavinia cuando es enterrada al pie del palo. Al unir estos dos elementos, Lavinia no muere, sobrevive al renacer su sangre en la naturaleza mezclada con la savia.

En cuanto a la segunda novela, Sofía de los presagios, esta se gesta en el momento en que la revolución está consolidada y la mujer comienza a ser destituida de cargos revolucionarios que se le habían otorgado (Isbester, 2001, p. 64). La novela está enfocada en una mujer que vive constantemente luchando en contra de los prejuicios sociales y el machismo en un pueblo rural. En comparación con la participación revolucionaria de Lavinia, Sofía ha sido abandonada en este pueblo al margen de la revolución, de la cual ella solo vive los ecos. Esto puede ser una crítica de Belli hacia lo que políticamente estaba pasando en 1987, cuando comenzaron los conflictos de las mujeres por la destitución de sus cargos en la agenda sandinista, que concluyen con la guerra de la Contra, la pérdida de poder en 1990 y la toma de la presidencia de Violeta Chamorro, a los cuales Belli responde con la publicación de sus dos obras Waslala y El país bajo mi piel (Isbester, 2001, p. 64).

En su entrevista con Hood, Belli comenta que con Sofía se enfoca en la simbología de la gitana en una trama fuera del ámbito político. Expande en el área de la feminidad la vinculación mágica de la 
mujer con la naturaleza y sus raíces, con el sentirse liberada y sin pertenecer a ningún grupo. Más adelante comenta que la revolución no obtuvo alcance en la vida nicaragüense del campo, en algunos lugares rurales, ni en pueblitos donde la vida y los cambios sociales transcurren con mucha lentitud. Agrega que quiso reflejar la dinámica entre Sofía y la reacción de un pueblo rural hacia ella, lo cual puede representar la sociedad nicaragüense moderna y su reacción contra las mujeres que se sienten muy seguras de sí mismas (1994, p. 128). A diferencia de la escritora, en este análisis trataré la obra como una novela política en la que se esconde una crítica a la revolución.

Sofía, de origen gitano-payo, queda abandonada en el pueblo de Diriá, posicionada como extraña, y el "otro". Su primer problema es enfrentar los prejuicios sociales y culturales. Sofía recuerda que para su padre la diferencia entre gitanos y payos residía en su carácter nómada o sedentario, que dotaba a los primeros de plenas libertades y a los segundos los llenaba de ataduras: "para los gitanos era cuestión de vivir cada día sin pensar para atrás, ni para adelante. Eso era ser gitano, le decía, esa era la diferencia con los payos que tenían que estar siempre en un lugar porque eran esclavos de lo que había pasado y lo que debía suceder" (Belli, 1992, p. 4). Sofía entra en conflicto con el pueblo, ya que ella no pertenece a la comunidad ni pertenece a su propia cultura por las raíces de su madre, que son payas, lo que la desubica desde su nacimiento.

En esta situación entran en fricción las tradiciones rurales de un pueblo y la resistencia de Sofía. Había creencias y prejuicios de los pobladores hacia grupos marginales como los gitanos: "Algunos se apartan y apartan a sus hijos de las puertas, les prohíben acercarse a la niña. Mal agüero, presagio extraño esa gitana apareciendo de la nada entre ellos. Parece cosa del diablo" (Belli, 1992, p. 17). El pueblo siempre la rechazó y la siguió muy de cerca para criticarla; debido a esto, Barbas-Rhoden dice que Sofía "attempts to negotiate her identity in a culture hostile toward her and in which she feels herself an outsider" [Intenta negociar su identidad en una cultura hostil hacia ella y en la que se siente una extraña] (Belli, 1992, p. 51). Sabemos que ella está consciente de esto y de la actitud que tiene ante la situación de abandono y rechazo: "Es que no entiendo... ¡Maldita mi madre que me dejó tirada y sin poder ser ni una cosa, ni la otra! (Belli, 1992, p. 244). Desde su abandono ella se queja y maldice a su madre, y se siente desubicada, no pertenece ni a su cultura paya-gitana ni a Diriá. Ella era una extraña en su sociedad y el rechazo del pueblo y el abandono de su madre son las razones por la cual ella lucha consigo misma y decide resistir.

Ante esta situación, considerando que no habrá nada que cambiase estos problemas, Sofía debe determinar aguantar o rebelarse. Arturo Arias compara este proceso en las protagonistas de $\mathrm{La}$ mujer habitada y Sofía, en que ambas "encuentran primero los límites y el confinamiento de la mirada del 'otro' que las cosifica y prejuicia su naturaleza. Ambas luchan consigo mismas para ubicarse ideológicamente en una situación que confronte dicha mirada" (Belli, 1992, p. 323). En adición, ellas buscan definirse a sí mismas y resistir a su entorno. El resultado es la resistencia de Sofía y la permanencia del atraso del pueblo de Diriá, ya que no sabemos de cambios sociales afectados por la revolución.

La segunda problemática que enfrenta la protagonista es el patriarcado y su manifestación del machismo en su esposo. El estado de tensión consiste en que: "Hay dos voluntades igualmente tercas en conflicto, el machismo indomable de René y la personalidad independiente de Sofía" (Miller, 1999, p. 65). De la tensión en el matrimonio, Arias comenta sobre el enfrentamiento del sujeto macho dominante versus la subjetividad femenina:

Aquí tenemos entonces a la parodia del sujeto macho que busca erigirse como dominante en la esfera pública y en la privada. Por extensión, florece la parodia de la racionalidad que articula la constitución de dicho sujeto. La ideología machista de la sociedad patriarcal es deconstruida pero no desde una antitética ideología feminista, sino desde una afirmación antinacionalista de la subjetividad femenina. (Belli, 1992, p. 319)

La tensión muestra dos problemáticas, la ideología machista de la sociedad patriarcal y la resistencia de Sofía, a la que Arias llama "afirmación antinacionalista de la subjetividad" (Arias, 1994, p. 319). Tomo el término de Arias para decir que Sofía tiene una subjetividad que es antinacionalista, porque 
está alejada de la lucha revolucionaria. Ella resiste demostrando que no necesita una revolución para hacerlo. La revolución no está haciendo nada por ella en este momento y ella no puede esperar a los cambios políticos en el pueblo para comenzar a sublevarse. Con el comportamiento resistente de Sofía, Belli afirma que la mujer, aún alejada del proyecto revolucionario y solo viviendo los ecos sigue luchando por adquirir la subjetividad de resistencia con la que se ha definido.

Sofía ha oído que por generaciones las brujas han ayudado a las mujeres por sus funciones encargadas de conservar la sabiduría ancestral, que desde tiempos remotos, antes de que se las persiguiera y se las obligara a la docilidad, veneraban la tierra y conocían el secreto de las buenas cosechas, los poderes mágicos de las plantas y las entrañas de ciertos animales. Debido a esto busca refugio en las montañas y ayuda a Xintal, una mujer indígena que la introduce en tradiciones ancestrales y en el recuerdo de su madre biológica.

Xintal afirma que le va a leer la Luna, el paso de las estaciones, las premoniciones sobre inviernos o sequías, así como el ciclo de las sangres menstruales y los partos (Belli, 1992). Aparte de esto, Sofía recibe consejos sobre cómo divorciarse, tomar decisiones y recobrar la memoria de su madre biológica. Xintal le dice: "La Diosa anda en los vientres de las mujeres... porque ahí es donde comienza la vida, desde donde todo lo que deseas se genera" (Belli, 1992, p. 125). A diferencia de la influencia de Itzá en la negación de la maternidad, los consejos de Xintal son orientados para que Sofía recuerde a su madre biológica y se busque la maternidad.

Al final de la novela el nacimiento de la hija de Sofía simboliza el mensaje de la permanencia en la resistencia y la llamada a la continuación de la lucha por nuevas generaciones. A pesar de que el deseo de la escritora era alejarse del ámbito político, ella no dejó de criticar en esta novela la falta de alcance político que tuvo la revolución en las áreas rurales. Su mensaje y deseo para las mujeres es de resistencia, lucha y participación política, o simplemente resistir como lo hizo Sofía, alejada de una revolución política.

\section{4. \\ Conclusiones. Después de la desilusión de la} política sandinista en 1990, Belli continuó su revolución literaria en Waslala (1996) y El país bajo mi piel (2001), en adición a Sofía y La mujer habitada. Las cuatro obras en conjunto recuperan y recrean memorias para futuras generaciones. Asimismo, Belli cumple con el acto de recordar, lo cual es importante en la escritura de la mujer para construir discursos que reten, se desliguen del patriarcado y reescriban la historia de la mujer como sujeto. A pesar de que no persistió el alcance revolucionario que tomara en cuenta los intereses de la mujer, su participación revolucionaria ha quedado como un "memorial para el futuro" de lo que puede ser, y de que aún en la desilusión se alberga la esperanza de continuar la resistencia. Este estudio es una puerta de entrada para analizar procesos sociales y políticos, entender el papel de la mujer en ellos y hacer una evaluación crítica de su participación incluso en momentos de desilusión.

\section{B. Bibliografía.}

Arias, Arturo. (1994). Gioconda Belli: La magia $\mathrm{y} /(\mathrm{d})$ el erotismo. La literatura centroamericana: Visiones y revisiones. Lewiston, NY: Mellen, 1994: 307-26.

Barbas-Rhoden, L. (2003). Writing Women in Central America. Gender and the Fictionalization of History. Athens: Ohio University Press.

Belli, G. (1998). Waslala. Barcelona: Salamandra.

Belli, G. (1996). La mujer habitada. Barcelona: Emecé.

Belli, G. (1992). Sofía de los presagios. México, D.F.: DIANA LITERARIA.

Bosé, C. E., \& Acosta-Belén, E. (1995). Women in the Latin American Development Process. Philadelphia: Temple University Press.

Craft, L. (1997). Novels of Testimony and Resistance from Central America. Gainesville: UP of Florida. 
Ferguson, W., \& Adams, R. E. (2001). Mesoamerica's ancient cities: aerial views of pre-Columbian ruins in Mexico, Guatemala, Belize, and Honduras Albuquerque: University of New Mexico Press.

Hirsch, M., \& Smith, V. (2002). Feminism and Cultural Memory: An Introduction Source: Signs. Gender and Cultural Memory, XXVIII (2), 1-19.

Hood, E. (1994). Entrevista con Gioconda Belli. Chasqui (23), 125-132.

Isbester, K. (2001). Still Fighting. Pittsburg: University of Pittsburg Press.

Lasarte Leonet, G. (2013). Gioconda belli, un universo de mujeres. Estudios Feministas, XXI(3), 1081-1097.

Merrill, T. (1993). Nicaragua: A Country Study. Washington: GPO for the Library of Congress.

Miller, M. B. (1999). Amor y erotismo en Sofía de los presagios de Gioconda Belli: Nuevos rumbos para la narrativa centroamericana en época de paz. Afrodita en el trópico. En Afrodita en el trópico: Erotismo y construcción del sujeto femenino en obras de autoras centroamericanas (págs. 61-73). Potomac, MD: Scripta Humanistica.

Molyneux, M. (2003). Women's movements in international perspective: Latin America and be yond. London: Institute of Latin American Studies Washington D.C.

Porter Weaver, M. (1993). The Aztecs, Maya, and Their Predecessors: Archaeology of Mesoamerica. San Diego: Stanford University Press.

Randall, M. (1991). Walking to the edge: essays of resistance. Boston: South End Press.

Randall, M., \& Yanz, L. (1994). Sandino's daughters: Testimonies of Nicaraguan women in struggle. Rutgers University Press. 